\title{
Teaching Transferable Skills to Doctoral Level Engineers-The Challenge and the Solutions
}

\author{
P. Kapranos \\ Department of Materials Science \& Engineering, The University of Sheffield, Sir Robert Hadfield Building, \\ Mappin Street, Sheffield, S1 3JD, UK \\ Email: p.kapranos@sheffield.ac.uk
}

Received April 2014

\section{Abstract}

At Sheffield University, we designed a "Skills Diploma" that supports and certifies our graduates in the areas of Transferable Skills. The Diploma in Personal and Professional Skills for Centers of Doctoral Training (CDT's) has been built into the 4-year PhD scheme in the following format: Part of the Diploma in Year one provides training in essential personal effectiveness skills to enable students to carry out their $\mathbf{P h D}$ research projects; training covers skills such as networking, communication \& presentation, motivation, assertiveness, project and time management and creative thinking and later in Year three, students build on the personal skills training delivered in year one and focus on professional skills required in business and industry. Students record their reflections and development in their Personal Development Planning (PDP) log supported by in-class and on line tutorials. A "blended learning" teaching approach is adopted with interactive sessions, including work in small groups, short presentations, individual reflection, plenary discussions and structured tasks. Students are encouraged to take a reflective approach to their learning and to identify their own additional training needs. A very important part of their learning experience is the SME Project where groups of students have to solve "real" problems and present their solutions within two working weeks. The teaching strategies and methods, learning objectives, assessment and feedback have all been constructively aligned within a flexible curriculum and we believe that the approach outlined above represents a paradigm shift in training tomorrow's leaders for UK industry.

\section{Keywords}

Transferable Skills, Personal Skills, Professional Skills, Blended Learning, Constructive Alignment

\section{Introduction-The Challenge}

Professor David Rae and his co-authors, in a recent paper entitled "Enterprise and Entrepreneurship in English Higher Education: 2010 and beyond" [1], observe that "the UK economy has shown very low levels of growth and recovery from the recession, thus presenting a major challenge for our graduates in their search for em- 
ployment and that graduates will require higher levels of skills in order to compete in the changing job market”.

The 2006 "Leitch Review of Skills" [2] also signaled the need towards specific workforce skills and a focus for up-skilling of graduates through to 2020, which prompted the Higher Education Funding Council for England "to develop a new co-funding model with employers for funding HE". The implementation of these reforms detailed in the White Paper "Students at the Heart of the System" [3] will have a significant impact upon business—university collaboration.

These calls for a greater emphasis on up-skilling of graduates are driven by the need of UK's ability to compete internationally and respond to the pressures of uncertainty and complexity induced by globalization of labor markets. There is a clear need for flexible and highly adaptable graduates who can think on their feet and be innovative in the current competitive global economic environment.

Academic institutions also have to respond to these challenges by revising their curricula and offering "more integration across subject areas, practice-based pedagogical tools, more teamwork learning opportunities, through collaboration with industry and business, that are meaningful, relevant and lead to lifelong learning skills" as proposed by The Oslo Agenda for Entrepreneurship Education in Europe (2006) [4]. That in effect means Educators themselves have to be trained to be enterprising and flexible, creating appropriate learning environments that enhance the student experience, while accommodating the needs for robust quality assurance mechanisms.

The European Parliament and the EU Council in December 2006, made a number of recommendations in the Key Competences Reference Framework of what our future graduates should possess: “... ability to turn ideas into action... have creativity, innovation and risk-taking, as well as the ability to plan and manage projects in order to achieve objectives. These [skills] support individuals, not only in their everyday lives at home and in society, but also in the workplace in being aware of the context of their work and being able to seize opportunities, and are a foundation for more specific skills and knowledge needed by those establishing or contributing to social or commercial activity. These should include awareness of ethical values and promoting good governance".

In UK and elsewhere we clearly need to re-think the way we train our engineers and more specifically our top engineers, those at doctoral level, to ensure that they become the leaders of tomorrow's industries, the "engines" of our economic recovery. Tryggvason \& Apelian, in their "Shaping our World" [5] propose that the engineer of this century is someone who:

1) Knows everything:

- Can find information about anything quickly.

- Knows how to evaluate \& use the information.

- Transform the information to knowledge.

2) Can do anything:

- Understands the engineering basics in order to assess what needs to be done.

- Can acquire the tools needed and use the proficiently.

3) Collaborates:

- Has communication \& team skills.

- Understands global issues and can work with anybody anywhere.

4) Innovates:

- Has imagination, entrepreneurial spirit and managerial skills to identify needs, come up with solutions and take them to the market.

Deliberately I specified above "our top engineers" because the challenge is to take our graduate engineers, who although very good, they are in general individuals who have learned how to successfully pass exams and graduate, and turn them into independent researchers at $\mathrm{PhD}$ level and instil in them not only the capacity of independent thinking but equipped with transferable career skills that will make them the successful leaders of our industrial future.

\section{The Sheffield Solution-Diploma in Personal \& Professional Skills within the Doctoral Training Centers (CDTs)}

\subsection{The Philosophy behind the Diploma}

One of the main tasks of the CDTs is to educate and train the industrial leaders of tomorrow. The expectation is 
that our CDT graduates not only will be equipped with the necessary technical knowledge and expertise but also with the appropriate transferable skills and enterprising attitude that will be key to leading the industrial resurgence and economic recovery in UK, the EU and the world in general [6]-[10].

We believe that learning is the modification of behavior through training, practice or experience, and as a result the CDT Diploma in Personal and Professional Skills has been devised to change the Knowledge, Attributes, Skills, and ultimately the Behavior of our students by learning "about the topic" (knowledge), "for the topic" (attributes), and "through the topic" (skills) [10] [11]. We also believe that the curriculum is never static and therefore it has to be flexible enough to accommodate changes as our students' progress through their Diploma studies (Figure 1) [12] and has to be clearly aligned as far as teaching strategies and methods, learning objectives, assessment and feedback (Figure 2). We endeavor to kindle in the students the desire to learn about the particular topic, instil or strengthen their self-belief, influence the willingness and attitudes towards learning, cultivate appropriate learning behaviors, and through reflection and conceptualization of their achievements of the various objectives start them on a virtuous journey of self-discovery, life-long learning and continuous personal improvement [10] [11].

\subsection{Constructive Alignment}

For an effective learning strategy we pursue "constructive alignment" of Learning Outcomes, Pedagogy (Learning Activities) and Assessment methods (Figure 3).

As already pointed out previously, one of the aims of our CDT Diploma is to equip our graduates with the transferable skills, as well as the technical knowledge and expertise they will need to succeed in their future careers and more widely in contributing to our industrial regeneration. In addition, some of the objectives are that CDT students to be able to:

- Identify their personal strengths and weaknesses

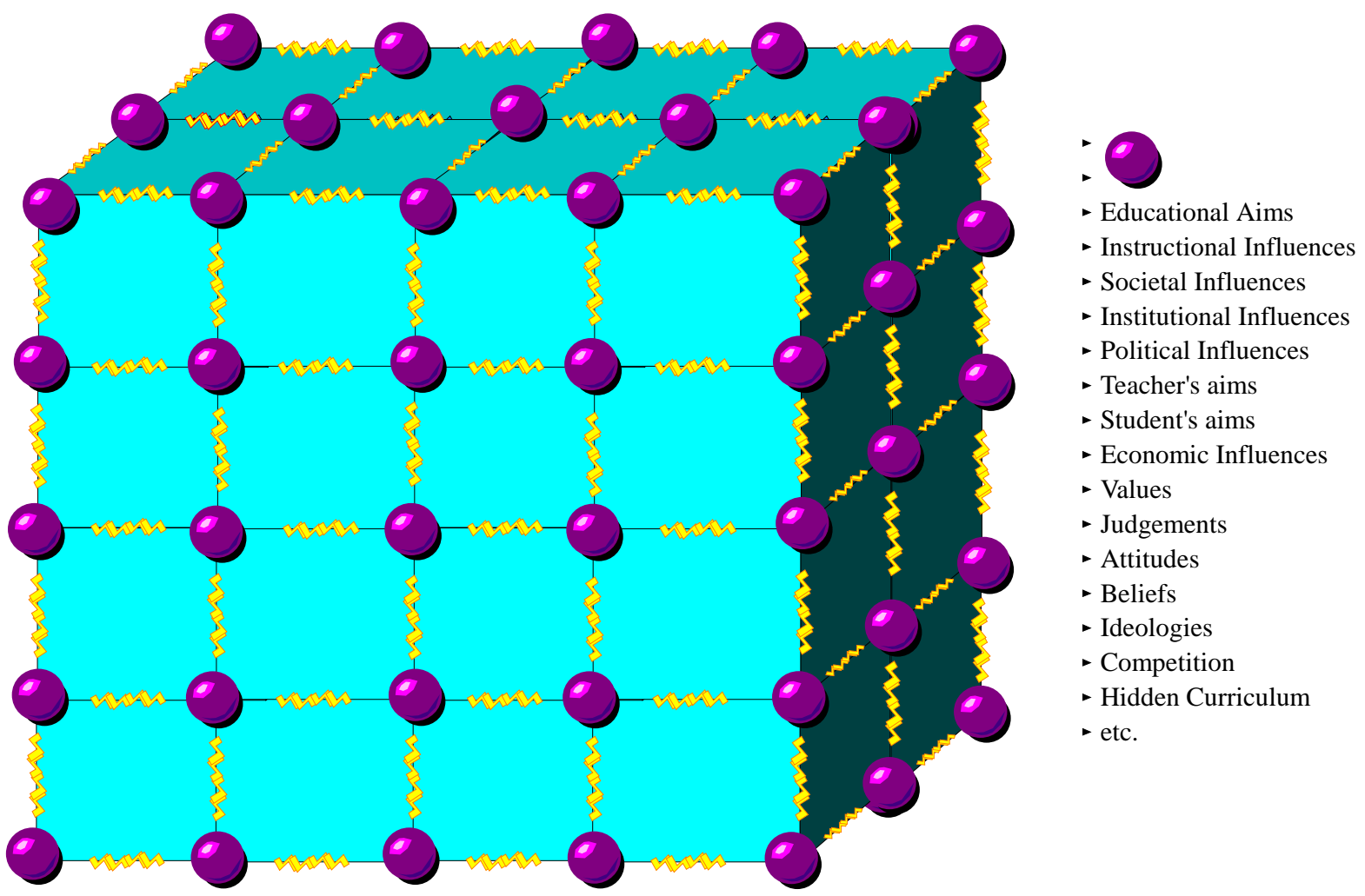

Figure 1. The curriculum as an atomic model continuum: The various factors that influence the curriculum are depicted as atoms within a lattice structure. All are interrelated and all affect each other in various ways. The influences act through the "springs" connecting the atoms. Movements result in compressions or stretches within the structure (pushes or pulls) which distort the lattice. However, given time the equilibrium can once again be reached and distortions removed. 
Learning in the curriculum: Formal learning, assignments, class work, group and individual projects, tasks, placements, reflective learning, self-directed learning, etc.

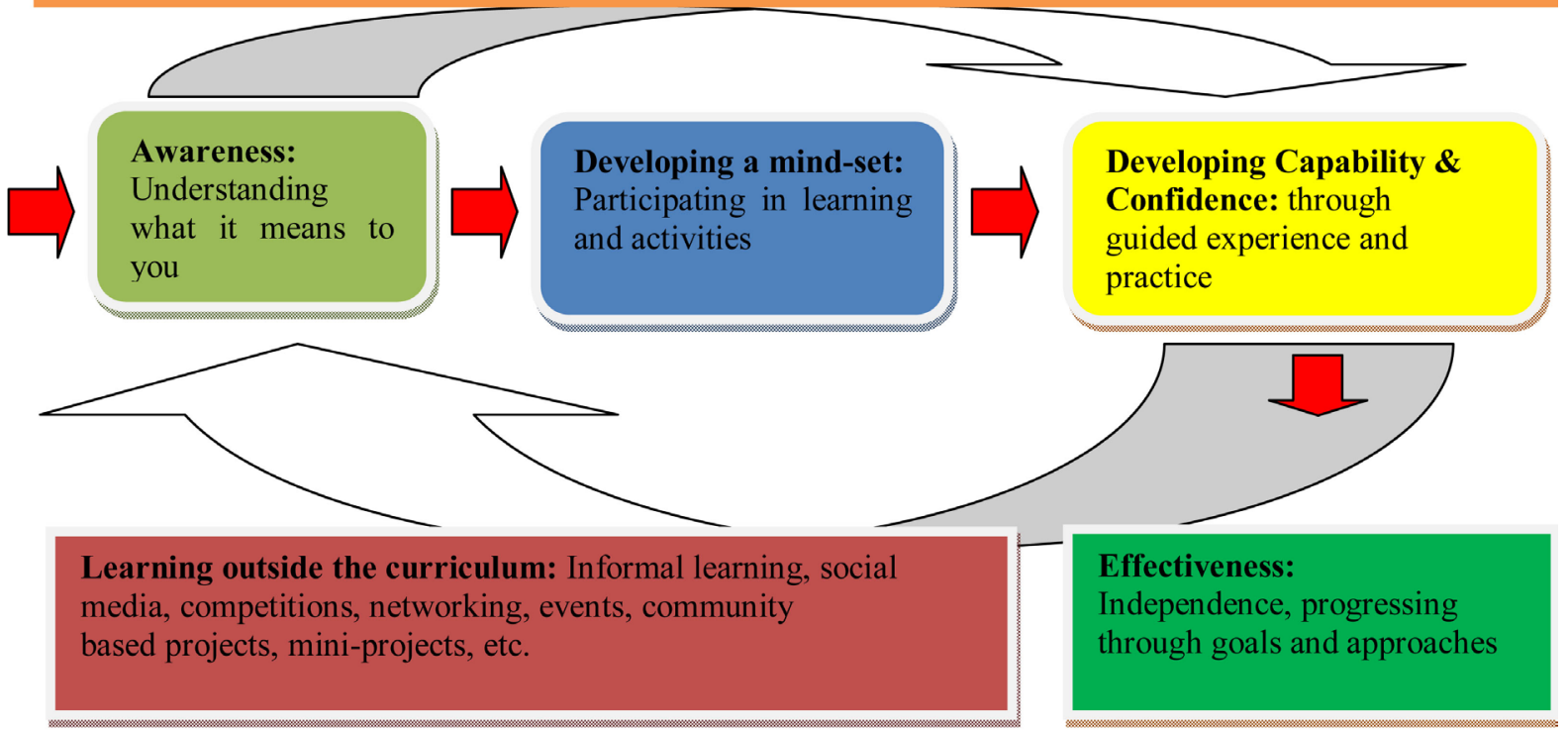

Figure 2. The curriculum as an atomic model continuum: The various factors that influence the curriculum are depicted as atoms within a lattice structure. All are interrelated and all affect each other in various ways. The influences act through the "springs" connecting the atoms. Movements result in compressions or stretches within the structure (pushes or pulls) which distort the lattice. However, given time the equilibrium can once again be reached and distortions removed.

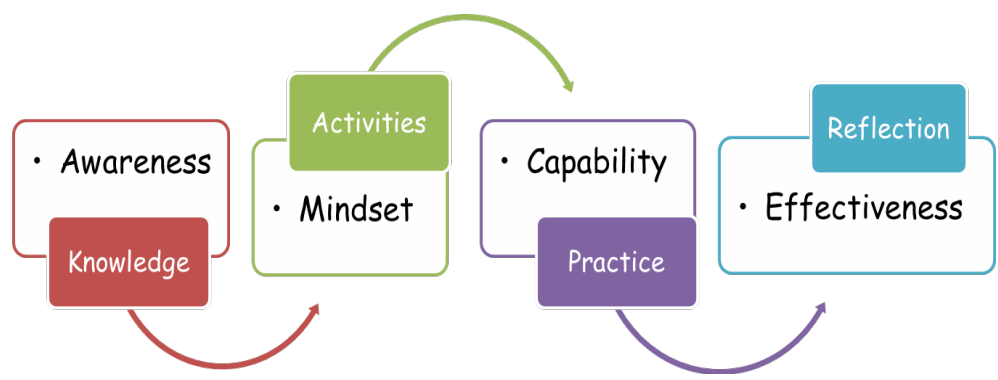

Figure 3. Connections between the "effectiveness" of the CDT graduates with the learning process.

- Display the skills and behaviors of future research leaders

- Identify and describe their skills and competencies to future employers

- Provide robust evidence of their achievements beyond standard technical competence

It is imperative that our "constructive alignment" approach has to provide not only clear links between the objectives and the educational methods used in achieving them, but also to the assessment process that verifies that the objectives are being met.

In developing the various workshops and exercises that will act as the main teaching vehicles, the educational objectives have been aligned with Bloom's Taxonomy as follows:

1) Knowledge (repeating verbatim): list, state, describe, define, identify...

2) Comprehension (demonstrating understanding of terms and concepts): Explain, interpret, summarize, and give examples...

3) Application (applying learned information): calculate, solve, apply, show, use, demonstrate...

4) Analysis (breaking things down to their elements, formulating theoretical explanations for observed phenomena): derive, explain, illustrate, select... 
5) Synthesis (creating something, combining elements in novel ways: formulate, design, devise...

6) Evaluation (making and justifying value judgments): select, compare, contrast, criticize...

In the same spirit of innovation, the assessment is also flexible and iterative and consists of:

- On line exercises,

- Occasional use of Electronic Voting Systems (Clickers) in class,

- Classroom individual and group exercises,

- Keeping a personal diary on the series of workshops and submission of a reflective portfolio indicating any changes in knowledge, behavior, and attitudes that are the result of the educational experience,

- A group exercise where the students have to solve a "real problem" in an industrial setting, and within two working weeks deliver solution(s) and be assessed on them by a panel of industrialists, academics and their peers. This innovation will be further explored in the next Module as an example of effectual thinking.

The various workshops undertaken by the students for transferable skill development are shown in Table 1 below:

The logic behind these workshops is that as the CDT students work as a cohort during their 1st year of studies and undergo training in specific technical fields that will be relevant to their future individual doctoral research, to be chosen towards the later part of year one, therefore the transferable skills modules are arranged to equip the students with skills that are generic and will be useful in facilitating their future research.

The students are given the tools of becoming more effective independent researchers and at the same time are imbued with the team ethos of working as a cohort as well as developing as individuals through confidence building exercises such as Mini-Research projects and Public Engagement Projects.

Towards the later part of their studies, the transferable skills become more focused in training the students to act with "professionalism" and therefore are closer to industry and its needs are as shown in Table 1, as well as other skills needed to complete their PhDs and seek employment, such as Thesis Writing Skills, Career Skills and the workings of Science \& Engineering and the Media.

During their induction week at the start of their CDT experience, the students are given to understand the philosophy behind the Diploma and how this fits in with their personal development as potential researchers and future industrial leaders. The modules are contextualized and the students not only can see the value of the intended set of skills but are made to make use of them from the beginning of their CDT studies. They are also clearly informed from the start on the need for assessment, the procedures that will be followed in having their work assessed as well as themselves assessing the work of their peers. Appropriate assessment methodology to any set objectives is very important as it is according to Graham Gibbs's "Dimensions of Quality" the most telling indicator of the quality of educational outcomes [13].

In relation to this, the educators and module developers have also done some soul searching and asked a lot of introspective questions up front in order to ensure that the linkages in our constructive alignment are relevant and robust (Table 2).

\section{Paradigm Shift}

A summary of the various objectives associated with the workshops outlined in Table $\mathbf{1}$ and their relationship to Bloom's Taxonomy has been given by Kapranos [14]. The objectives have been based on the Vitae Researcher Development Framework [15] and as it can be seen the objectives have evolved to the current ones through a

Table 1. Workshops undertaken during the diploma in personal \& professional skills.

\begin{tabular}{cc}
\hline Specific skills for Year 1 & Specific skills for Year 3 \\
\hline 1) Networking skills & 1) Attracting research funding \\
2) Working in teams & 2) Intellectual property \& knowledge transfer \\
3) Communication \& presentation skills & 3) Enterprise \& business planning \\
4) Time management & 4) Project management \& financial management \\
5) Project management & 5) Health \& safety at work \\
6) Creative thinking & 6) Conflict resolution \& negotiation \\
7) Getting motivated & 7) Facilitation \\
8) Assertiveness & 8) Creativity, innovation, enterprise \\
\hline
\end{tabular}


Table 2. Information used in ensuring constructive alignment in the CDT Diploma.

The educators reflect on:
- Are you aware of what skills you are supposed to
teach?

Review and Reflection Process in line with our belief and commitment to a flexible evolutionary curriculum.

In addition to the above, we also believe that with the opportunity afforded to us through the development of the CDT Diploma we are in a position to carry out our own research into the transition of graduate students to independent research scholars and future leaders of industry and as we intend to follow up the future career paths of our graduates we can carry out a longitudinal study on the effectiveness and success or otherwise of our Diploma in Personal \& Professional Skills towards these ends.

\subsection{Developing Independent Researchers}

Traditional PhD research, carried out around the world, involves a student working on a specific topic under the supervision of one or more academics with the basic task of making an "original contribution to knowledge” and the underlying philosophical basis of $\mathrm{PhD}$ research being "the production of creative scholars" or "preparation of students for a lifetime of intellectual inquiry that manifests itself in creative scholarship and research" [16]. However, not all students undertaking PhD level research find the transition from "UG course followers" to PG "producers of knowledge" to be an easy one. In addition, excellent performance at the UG level, although a good indicator of intellectual capability, does not appear to be a guarantee of success in making the transition to independent scholarship.

The diagram in Figure 4 relates the performance, effectiveness, and achievement of independent research scholarly status against a time scale, as experienced by $\mathrm{PhD}$ supervisors and their typical PhD students. These experiences consistently show that $\mathrm{PhD}$ students not only take time to adjust to their new status of producer of knowledge and independent researcher but occasionally the transition is never achieved. The last 10 years has seen the majority of the UK Research Councils initiate enhanced graduate research training programs through the development of Centers for Doctoral Training (CDTs). Unlike a traditional PhD route, students enter a CDT as a cohort and undertake a substantive $\mathrm{PhD}$ level research project together with additional individual and group training activities. These typically include taught coursework, training in a wide range of transferable skills to enhance their research efficiency and industrial readiness levels, and group activities such as outreach projects to engage the public in science and engineering. In most cases CDTs are based around a multidisciplinary theme and have an intake of around 10 - 20 students per year and expect completion of the PhD within 4 years. The multidisciplinary nature means students have a wide range of first degrees; thus, the first 6 to 12 months of the program are generally front-loaded with technical training as well as soft skills courses to fast track the transition to independent research.

A number of independent researchers have investigated the possible reasons behind successful or not successful transitions to independent scholarship [17]-[23] and although they have offered explanations, as well as useful advice, they all agree with the need for further research. This research has provided us with evidence that there is no single characteristic indicator for the transition to "independent scholar" and that the transition process is influenced by a variety of factors in the macro and micro-environments associated with the process. The evidence also shows that relationships and interactions within the micro-environment are key resources to the transition process. There is clear agreement in the literature that more research is necessary to provide back-up evidence for these "socialization models", as well as unpicking the degree of influence the various proposed factors have on the transition.

The CDT cohort setting provides us with a unique situation that brings together all the macro and microenvironmental elements used in previous research but with additional layers for data collection such as the CDT Management Team, the Industrial Sponsors and Industrial Supervisors. These extra layers, in addition to the typical sources of data collection from CDT academic staff and students, allows methodological triangulation that might balance out potential weaknesses in our data collection methods. We believe that the interactions 


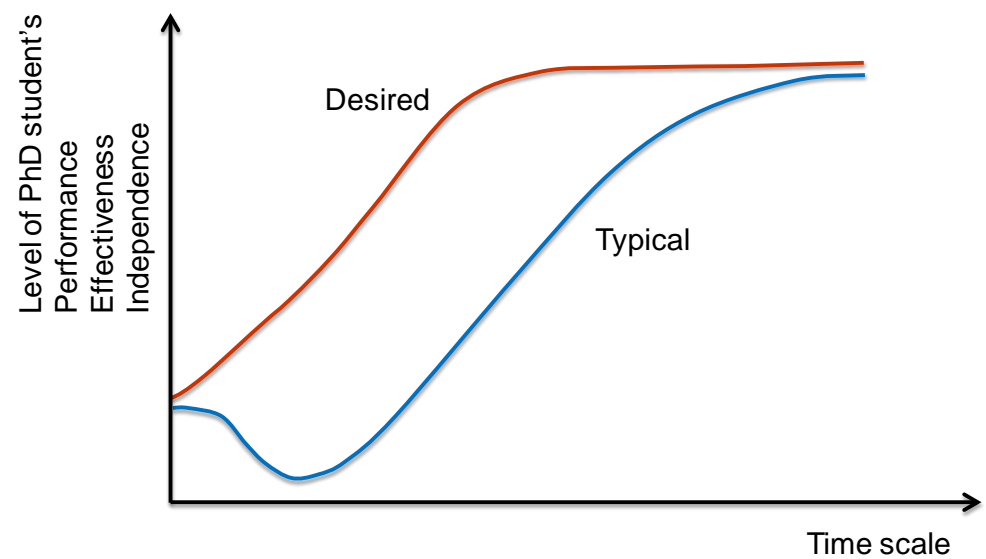

Figure 4. Progress of performance, effectiveness and independence of doctoral students with time.

of all participants within the social structure of the CDT cohort environment provide aspects that are probably unique, individual and qualitative and by adapting multiple research methodologies we will be able to explore and unpick people's multiple perspectives in the social setting of our CDT cohorts that will allow the emergence of models from the data to be used not only in the CDT setting but in any setting that has fast-track transition to independent research scholarship as its target. Our CDT setting will provide high quality long term data collection over a 4-year PhD studentship period and we expect to follow through with data collection after graduation to verify that we are indeed producing independently thinking individuals. This puts us in the unique situation of having a large pool of students at all the various stages of the $\mathrm{PhD}$ process who can provide substantial amounts of data on what might be the ingredients for their successful transition to independent research scholars.

\subsection{SME Case Studies}

We earlier stated our belief that learning is the modification of behavior through training, practice or experience, and our approach to change the Knowledge, Attributes, Skills, and ultimately the Behavior of our students by learning "about the topic" (knowledge), "for the topic" (attributes), and "through the topic" (skills). True to our belief that the curriculum is never static and therefore it has to be flexible enough to accommodate changes as our students' progress through their studies through a Review and Reflection Process, together with feedback from the early CDT cohorts, in line with our belief and commitment to a flexible evolutionary curriculum we decided on a particular evolution that is compatible with the topic of effectuation.

The originally conceived 11 workshops (modules) for the CDT year three students have been reduced to eight but the freed up time has been used to introduce the students to a hands on case of effectuation. The students are split into groups of 4 - 5 and are sent to an SME with the remit of solving a particular problem pertinent to the company. The students are given 2 working weeks (10 days) to analyze the problem and come up with solutions. They quickly come to realize that they have to act with what is available to them. Sarasvathy [24] describes "Effectual reasoning" as "a process where entrepreneurs begin with three categories of means: 1) Who they aretheir traits, tastes and abilities; 2) What they know-their education, training, expertise, and experience; and, 3) Whom they know-their social and professional networks. Using these means, the entrepreneurs begin to imagine and implement possible effects that can be created with them. Most often, they start very small with the means that are closest at hand, and move almost directly into action without elaborate planning. Unlike causal reasoning that comes to life through careful planning and subsequent execution, effectual reasoning lives and breathes execution. Plans are made and unmade and revised and recast through action and interaction with others on a daily basis. Yet at any given moment, there is always a meaningful picture that keeps the team together, a compelling story that brings in more stakeholders and a continuing journey that maps-out uncharted territories. Through their actions, the effectual entrepreneurs' set of means and consequently the set of possible effects change and get reconfigured. Eventually, certain of the emerging effects coalesce into clearly achievable and desirable goals-landmarks that point to a discernible path beginning to emerge in the wilderness". 
If one were to substitute "CDT students" instead of entrepreneurs in the above description of "Effectual reasoning" they would be providing a very accurate picture of what the groups of CDT students experience in their 2 week SME case studies. This approach was introduced last year and it was successfully completed with both students and SMEs concerned highly valuing the experience. The students enjoyed the action learning scenario where they had to bring into play skills they have and ones they did not know they possessed. The groups were energized by the real nature of the exercise and the fact that they had to behave and act like professionals and act under real time constraint ( 2 week delivery deadline) to deliver solutions that were feasible not only technically but financially. The SMEs that participated were also amazed that in the limited time afforded our students they were able to use their knowledge and skills to obtain the resources needed to come up with feasible solutions to the problems they were given (Figure 5).

\section{In Conclusion}

The Diploma in Personal \& Professional Skills for the Doctoral Training Centers (CDTs) has been designed around existing official guidelines and the wider literature with a philosophy of "blended learning" and "constructive alignment" of Learning Outcomes, Pedagogy (Learning Activities) and Assessment methods. The educational philosophy outlining our goals, values and attitudes is offered as proof of the professionalism in our approach as proposed by Hannon [25] and further proof is the use of a wide variety of pedagogies.

Individual workshops and activities are linked to the skills to be taught under the various modules. Clearly, the ownership conferred by student chosen projects act as an excellent intrinsic motivator and a reliable scaffold on which to hang the various skills we would like our CDT students to possess and have practiced at the end of their studies.

The use of the SME case studies as a vehicle of development of "skills in action" is consistent with Whitehead's notions of educational aims [26] that "... there is only one subject matter for education, and that is Life in all its manifestations". This approach does indeed attempts, as Whitehead suggests, teaching the students via "Real Life Experiences", create for them "appreciation by use", the students "gain their knowledge quickly and then use it"' and "as they use it, they retain it". Whitehead also gives fair warning that this is not an easy task: "Education is the acquisition of the art of the utilization of knowledge. This is an art very difficult to impart". It is encouraging that the early success of this approach and the positive all round response seems to indicate that a number of boxes are being ticked and although difficult, the acquisition of knowledge through use is definitely being imparted in this process.

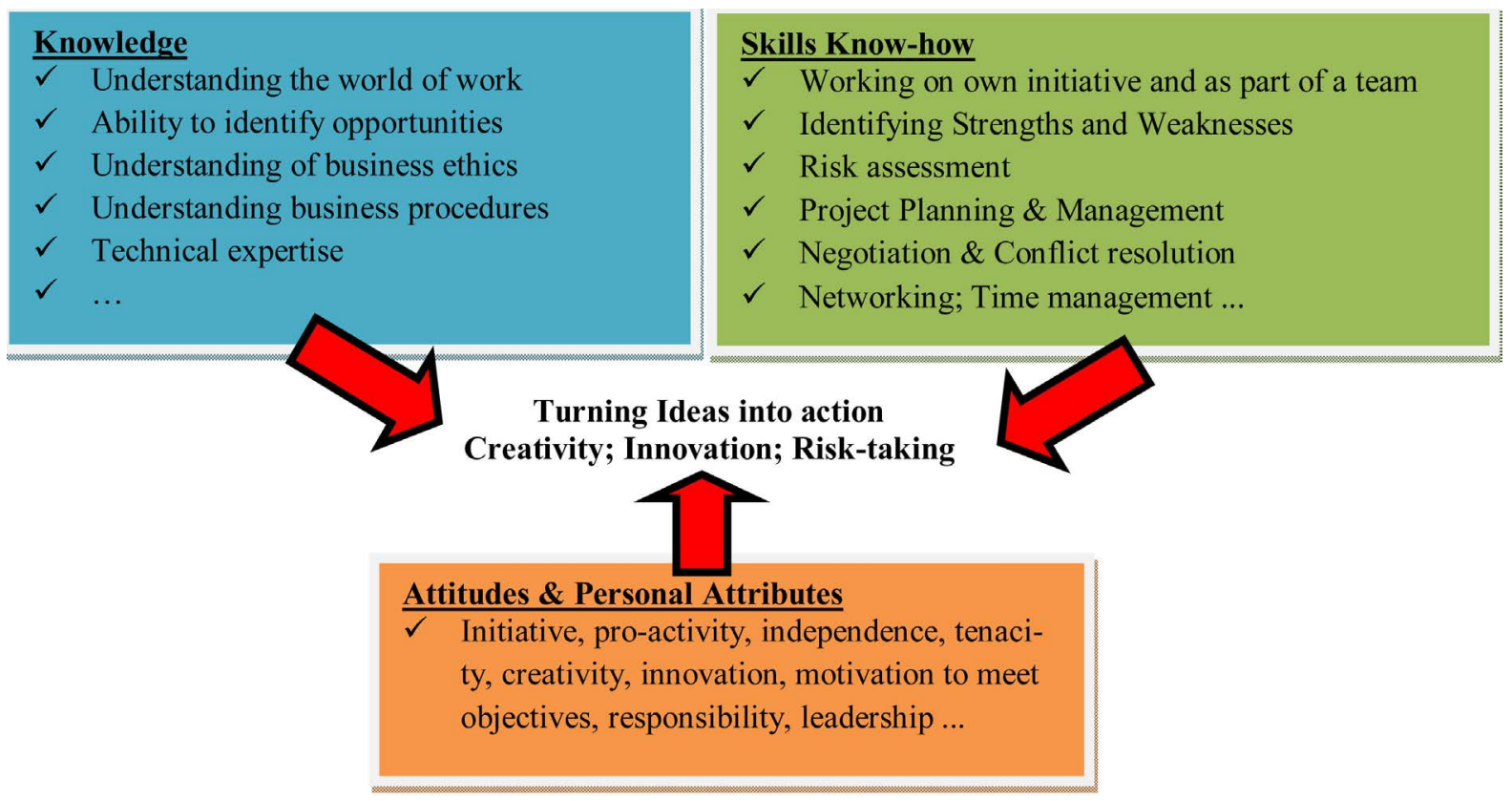

Figure 5. The educational aspects of the SME case studies. 
The CDT Diploma affords us a unique opportunity to carry out research into the transition of graduate students to independent research scholars and future leaders of industry and as we intend to follow up the future career paths of our graduates we can carry out a longitudinal study on the effectiveness and success or otherwise of our Diploma in Personal \& Professional Skills towards these ends.

Recent adjustments to our existing CDT modules have been highly influenced and consistent with Gibb's "Towards the Entrepreneurial University" [9] and QAA's "Enterprise and entrepreneurship education: Guidance for UK higher education providers" [11]. This is once again an example of our ever evolving flexible curriculum together with further proof of our constructively aligned enterprising educational philosophy.

\subsection{Authors and Affiliations}

Dr. Plato Kapranos, Senior University Teacher, Department of Materials Science \& Engineering, The University of Sheffield, Sir Robert Hadfield Building, Mappin Street, Sheffield, S1 3JD, Yorkshire, UK. Email: p.kapranos@sheffield.ac.uk

\section{Acknowledgements}

Thanks to all the colleagues who have interacted with me in the CDT project and to our students who have been part of these exciting developments in the shared Teaching \& Learning experience and last but not least EPSRC for their farsightedness in funding the Centers for Doctoral Training.

\section{References}

[1] Rae, D., Martin, L., Antcliff, V. and Hannon, P. (2012) Enterprise and Entrepreneurship in English Higher Education: 2010 and beyond. http://www.academia.edu/2691357/Enterprise_and_entrepreneurship_in_English_higher_education_2010_and_beyond

[2] (2006) Leitch Review of Skills—Prosperity for All in the Global Economy—World Class Skills, Final Report. http://www.delni.gov.uk/leitch_finalreport051206[1]-2.pdf

[3] (2011) Higher Education: Students at the Heart of the System. Presented to Parliament by the Secretary of State for Business, Innovation and Skills by Command of Her Majesty.

https://www.gov.uk/government/uploads/system/uploads/attachment_data/file/31384/11-944-higher-education-students -at-heart-of-system.pdf

[4] (2006) Entrepreneurship Education in Europe: Fostering Entrepreneurial Mindsets through Education and Learning. Final Proceedings, OSLO, 26-27 October.

http://ec.europa.eu/enterprise/policies/sme/files/support_measures/training_education/doc/oslo_report_final_2006_en.p $\underline{\mathrm{df}}$

[5] Tryggvason, G. and Apelian, D. (2012) Shaping Our World. John Wiley\& Sons.

[6] (2012) Effects and Impact of Entrepreneurship Programs in Higher Education, Brussels, March, Published by the Entrepreneurship Unit, Directorate-General for Enterprise and Industry, European Commission.

[7] O’Leary, D. \& Wind-Cowie, M. (2012) Everyone’s Business. DEMOS. www.demos.co.uk

[8] (2013) Enterprise Education Impact in Higher Education and Further Education. Final Report, Department for Business Innovation and Skills. https://www.gov.uk/government/organisations/department-for-business-innovation-skills

[9] Gibb, A. (2005) Towards the Entrepreneurial University: Entrepreneurship Education as a Lever for Change. National Council for Graduate Entrepreneurship. www.ncge.org.uk

[10] (2012) Building Entrepreneurial Mindsets and Skills in the EU. Guidebook Series on "How to support SME Policy from Structural Funds”. Directorate-General for Enterprise and Industry, European Commission.

[11] (2012) QAA Enterprise and Entrepreneurship Education: Guidance for UK Higher Education Providers. The Quality Assurance Agency for Higher Education. www.qaa.ac.uk

[12] Kapranos, P. (2003) The Contrasting Roles of the Teacher in Conventional and Distance Learning Set-Ups. Master of Education in Teaching \& Learning, The University of Sheffield.

[13] Gibbs, G. (2010) Dimensions of Quality. The Higher Education Academy. www.heacademy.ac.uk

[14] Kapranos, P. (2012) Diploma in Personal and Professional Skills for Centers of Doctoral Training — Managing by Instructional Objectives. Proceedings of 4th International Symposium for Engineering Education, July 2012, UK, 307315.

[15] Vitae Researcher Development Framework. www.vitae.ac.uk/rds 
[16] Bargar, R.R. and Duncan, J.K. (1982) Cultivating Creative Endeavor in Doctoral Research. The Journal of Higher Education, 52, 1-31. http://dx.doi.org/10.2307/1981536

[17] Lovitts, B.E. (2008) The Transition to Independent Research: Who Makes It, Who Doesn’t and Why. The Journal of Higher Education, 79, 296-325. http://dx.doi.org/10.1353/jhe.0.0006

[18] Lovitts, B.E. (2005) Being a Good Course Taker Is Not Enough: A Theoretical Perspective on the Transition to Independent Research. Studies in Higher Education, 30, 137-154. http://dx.doi.org/10.1080/03075070500043093

[19] Gardner, S.K. (2008) What's Too Much and What's Too Little?: The Process of Becoming an Independent Researcher in Doctoral Education. The Journal of Higher Education, 79, 326-350. http://dx.doi.org/10.1353/jhe.0.0007

[20] Baker, V.L. and Pifer, M.J. (2011) The Role of Relationships in the Transition from Doctoral Student to Independent Scholar. Studies in Continuous Education, 33, 5-17. http://dx.doi.org/10.1080/0158037X.2010.515569

[21] Sweitzer, V. (2009) Towards a Theory of Doctoral Student Professional Identity Development: A Developmental Networks Approach. The Journal of Higher Education, 80, 1-33. http://dx.doi.org/10.1353/jhe.0.0034

[22] Hopwood, N. and Sutherland, K. (2009) Relationships and Agency in Doctoral and Early Career Academic Experience. Proceedings of 32nd HERDSA Annual Conference, 6-9 July 2009, Darwin, 210-218.

[23] Golde, C.M. (1998) Beginning Graduate School: Explaining First-Year Doctoral Attrition. New Directions in Higher Education, 1998, 55-64. http://dx.doi.org/10.1002/he.10105

[24] Saravathy, D. (2008) What Makes Entrepreneurs Entrepreneurial? 1-9. http://ssrn.com/abstract=909038

[25] Hannon, P.D. (2006) Teaching Pigeons How to Dance: Sense and Meaning in Entrepreneurship Education. Education \& Training, 48, 296-308. http://dx.doi.org/10.1108/00400910610677018

[26] Whitehead, A.N. (1929) The Aims of Education and Other Essays. Free Press, paperback Edition, 1967. 